\title{
Effect of erythropoietin on human tumor growth in xenograft models
}

\author{
MOTOYUKI KATAOKA, YOICHIRO MORIYA, YOSHIYUKI MORIGUCHI, TOSHIKI IWAI, \\ KAORI FUJIMOTO-OUCHI, MASATOSHI SHIRANE, KUMIKO KONDOH and KAZUSHIGE MORI
}

Product Research Department, Chugai Pharmaceutical Co., Ltd., Shizuoka 412-8513, Japan

Received June 2009; Accepted September 10, 2009

DOI: $10.3892 / \mathrm{mmr} \_00000224$

\begin{abstract}
Recombinant human erythropoietin (rhEPO) has been used in the EU and the United States for the treatment of anemia in cancer patients after myelosuppressive chemotherapy or radiotherapy. However, several conflicting results have been reported concerning the detrimental effect of rhEPO on survival benefit in cancer patients. In experimental studies, contradictory results were also reported in in vitro tumor cell proliferation studies and in vivo tumor growth studies using tumor cells expressing EPO-receptor (EPO-R). Therefore, we tried to clarify the effect of epoetin $\beta$, a product of rhEPO, on tumor growth in xenograft models using five EPO-R-positive human cancer cell lines, namely the MCF7 breast, 786-O renal, SCH gastric, A549 lung and SK-OV-3 ovarian cancer cell lines. Epoetin $\beta$ was administered once a week for 3 weeks at doses of 1,000, 3,000 and 10,000 IU/kg in accordance with the clinical administration schedule and dosages. As a result, no enhancement of tumor growth from the administration of epoetin $\beta$ was observed in any of the xenograft models throughout the experiment duration. The effect of epoetin $\beta$ on the antitumor activity of bevacizumab, an anti-angiogenic agent, was additionally examined using A549 and MCF7 xenograft models, since rhEPO reportedly stimulates tumor neovascularization. Epoetin $\beta$ showed no significant effect on the antitumor activity of bevacizumab in either xenograft model. These findings suggest that epoetin $\beta$ is not involved in in vivo tumor growth promotion.
\end{abstract}

\section{Introduction}

Erythropoietin (EPO) is a 30.4-kDa glycoprotein that promotes the proliferation, differentiation and maturation of erythroid progenitor cells by binding to its cognate cell surface EPO receptor (EPO-R) (1-4). Recombinant human EPO (rhEPO) is

Correspondence to: Dr Motoyuki Kataoka, Product Research Department, Chugai Pharmaceutical Co., Ltd., 1-135 Komakado, Gotemba, Shizuoka 412-8513, Japan

E-mail: kataokamty@chugai-pharm.co.jp

Key words: epoetin $\beta$, human cancer xenograft, erythropoietin receptor, bevacizumab an effective treatment modality of anemia associated with chronic renal failure (5) and is used in the EU and the United States for the treatment of anemia in cancer patients who have received myelosuppressive chemotherapy or radiotherapy. Anemia associated with cancer and cancer therapy is one of the independent prognostic factors in the treatment of malignant diseases. Several studies have shown that administration of rhEPO to cancer patients with chemotherapy-related anemia increased hemoglobin $(\mathrm{Hb})$ concentration, resulting in reduced need for blood transfusions and improved quality of life (QOL) (6-11). However, conflicting results have been reported concerning the overall survival of patients who have received rhEPO therapy. A recent meta-analysis suggested that the treatment of anemia with rhEPO may improve overall survival in cancer patients (12). Moreover, Glaser et al demonstrated that overall survival was prolonged in the rhEPO-treated group compared with the non-treated group in patients with squamous cell carcinoma of the oral cavity and oropharynx who had received chemo-radiation therapy (13). On the other hand, data from several clinical trials indicated adverse outcomes. Henke et al described that locoregional progression-free survival was poorer in a rhEPO (epoetin $\beta$ ) group than in a placebo group in patients with advanced head and neck cancer who had received definitive treatment with radiotherapy or postoperative radiotherapy (ENHANCE Study) (14). Leyland-Jones et al reported a higher mortality in a group treated with rhEPO (epoetin $\alpha$ ) compared with a placebo group in patients with metastatic breast cancer (BEST Study) (15). Wright et al observed a decrease in overall survival in patients with advanced non-small cell lung cancer treated with rhEPO (epoetin $\alpha$ ) (16). The disparities may be attributed to differences in study population, design, target $\mathrm{Hb}$ level and risk of thromboembolic complications, and there is concern that rhEPO may stimulate tumor growth. However, whether or not EPO directly promotes tumor growth by binding to EPO-R expressed on tumor cells, which may lead to clinical progression in cancer patients, remains unclear. The Oncologic Drug Advisory Committee (USA) has indicated that there are insufficient data from adequate and well-controlled studies designed to assess the effects on survival or tumor promotion, and employ the recommended doses of erythropoiesis-stimulating agents (17). In addition, the United States Food and Drug Administration issued a warning against erythropoiesis-stimulating agents for patients with chemotherapy-associated anemia (18). 
Recently, EPO-R expression has been demonstrated in several non-hematopoietic tissues, including brain and cardiovascular tissues, vascular endothelial cells and erythroid cells (19-23). The expression of functional EPO-R was also demonstrated in various human tumor cells, including breast, renal, gastric, lung, ovarian, skin and prostate cancer cells (24-30). Studies have shown that EPO enhanced the in vitro proliferation of EPO-R-positive breast and renal cancer cells $(25,27)$. In addition, Arcasoy et al reported that administration of a neutralizing anti-EPO antibody or soluble EPO-R suppressed the growth of breast cancer cells in a tumor Z-chamber model in rats (24). In contrast, other researchers have reported that rhEPO does not affect tumor cell proliferation in vitro $(31,32)$ or in vivo (33-35). Moreover, Mittelman et al suggested that rhEPO may improve overall survival in a murine myeloma model (36). Thus, there is controversy as to whether EPO/EPO-R is involved in tumor growth or not. In addition to direct tumor cell proliferation stimulation, EPO has been shown to promote the growth of tumors by enhancing angiogenesis (37).

Here, we examined the effect of exogenous rhEPO (epoetin $\beta$ ) treatment on the in vivo growth of human breast (MCF7), renal (786-O), gastric (SCH), lung (A549) and ovarian (SK-OV-3) cancer cell lines, as well as the effect of EPO on the antitumor activity of an anti-angiogenesis agent (bevacizumab) in mouse xenograft models.

\section{Materials and methods}

Animals. Male and female 5-week-old BALB/c-nu/nu mice (CAnN.Cg-Foxn1(nu)/CrlCrlj nu/nu) were obtained from Charles River Laboratories Japan, Inc. (Yokohama, Japan). Animals were housed in a pathogen-free environment under control conditions (temperature $20-26^{\circ} \mathrm{C}$; humidity $40-70 \%$; light-dark cycle 12-12 h). Chlorinated water and irradiated food were provided ad libitum. The animals were allowed to acclimatize and recover from shipping-related stress for 1 week prior to the study. The health of the mice was monitored by daily observation.

The study protocol was reviewed by the Institutional Animal Care and Use Committee of Chugai Pharmaceutical Co., Ltd. and all animal experiments were performed in accordance with the Guidelines for the Accommodation and Care of Laboratory Animals promulgated by Chugai Pharmaceutical Co., Ltd.

Cell lines and culture conditions. Five human cancer cell lines were used in the present study. MCF7 human breast cancer cells were kindly provided by Dr Y Iino (Gunma University, Maebashi, Japan) and were maintained in Eagle's Minimum Essential medium (MEM; Sigma-Aldrich Inc., MO, USA) supplemented with $0.1 \mathrm{mmol} / \mathrm{l} \mathrm{MEM}$ non-essential amino acids (Invitrogen Corp., CA, USA), $1 \mathrm{mmol} / 1$ sodium pyruvate (Invitrogen) and 10\% (v/v) fetal bovine serum (FBS; Thermo Trace Ltd., Victoria, Australia). 786-O human renal cancer cells were purchased from the American Type Culture Collection (ATCC; Manassas, VA,USA) and were maintained in RPMI-1640 medium (Sigma-Aldrich) supplemented with $4.5 \mathrm{~g} / \mathrm{l}$ D-glucose (Sigma-Aldrich), $10 \mathrm{mmol} / \mathrm{l}$ HEPES buffer (Sigma-Aldrich), $1 \mathrm{mmol} / 1$ sodium pyruvate (Invitrogen) and $10 \%$ FBS. SCH human gastric cancer cells were obtained from the Health Science Research Resources Bank (Osaka, Japan) and were maintained in RPMI-1640 medium supplemented with $10 \%$ FBS. A549 human lung cancer cells were purchased from ATTC and were maintained in F12K Nutrient Mixture medium (Invitrogen) supplemented with 10\% FBS. SK-OV-3 human ovarian cancer cells were purchased from ATCC and were maintained in BALB/c-nu/nu mice by the subcutaneous inoculation of tumor fragments.

Chemicals. Epoetin $\beta$ (Chugai Pharmaceutical Co.,Ltd., Tokyo, Japan) was diluted in vehicle to achieve the appropriate concentration for administration. Vehicle was prepared by dissolving

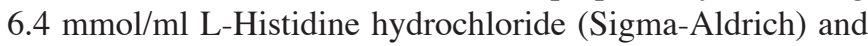
$0.005 \%$ Tween-80 (Sigma-Aldrich) in phosphate-buffered saline and then sterilized through filtration (pore size $0.02 \mu \mathrm{m}$; Millipore Corp., MA, USA). Bevacizumab (Chugai), an antiVEGF monoclonal antibody, was diluted in saline.

Detection of EPO-R by RT-PCR. To examine the EPO-R expression of tumor cells in terms of mRNA, total RNA was isolated from each tumor cell line cultured in vitro using Sepasol-RNA I (Wako Pure Chemical Industries, Osaka, Japan). Reverse transcription PCR (RT-PCR) was performed according to the method reported by Yasuda et al (26). Briefly, total RNA was reverse transcribed to cDNA using oligo-dT primer and Superscript II (Invitrogen). The PCR-amplification primers for EPO-R were forward primer 5'-GAAGTAGTGCTCCTAGACGCC-3' and reverse primer 5'-CGGCTCCACTGCCTGCATCG-3'. The PCR reaction was performed at $95^{\circ} \mathrm{C}$ for $10 \mathrm{~min}$ followed by 45 cycles at $95^{\circ} \mathrm{C}$ for $30 \mathrm{sec}, 63^{\circ} \mathrm{C}$ for $30 \mathrm{sec}$ and $72^{\circ} \mathrm{C}$ for $60 \mathrm{sec}$ using a Zymoreactor II (Atto Corp., Tokyo, Japan). Samples were electrophoresed in $1.5 \%$ agarose gel and were visualized with ethidium bromide. RT-PCR of $\beta$-actin was carried out as a control.

Hematopoietic effect of epoetin $\beta$ in BALB/c-nu/nu mice. Male BALB/c-nu/nu mice were divided into 40 sets of 6 . To avoid the artificial effect of frequent hematological analyses (endogenous production of EPO), samples of blood were obtained from all mice in each set for every sampling point. Epoetin $\beta$ was subcutaneously administered once a week for 4 weeks. Mice were anesthetized with diethyl ether (Wako Pure Chemical) prior to bleeding, and $0.6 \mathrm{ml}$ of blood was collected from the posterior vein every day for the first week and twice a week for the second through fourth weeks. EDTA (Dojindo Laboratories Co., Ltd., Kumamoto, Japan) was used as the anticoagulant. The determination of $\mathrm{Hb}$ concentration, hematocrit and red blood cell count (RBC) was conducted on the blood samples using an ADVIA 120 automated blood analyzer with murine software (Bayer Medical Co. Ltd., Tokyo, Japan).

Human cancer xenograft models and epoetin $\beta$ treatment. MCF7 cells were subcutaneously inoculated at 5x106 cells/ mouse into the right flanks of female mice that had been implanted with slow-release estrogen pellets $(0.25 \mathrm{mg} 17 \beta$ estradiol; Innovative Research of America, OH, USA) the day before tumor cell inoculation. Male mice were subcutaneously inoculated into the right flank with $1 \times 10^{7}$ cells/mouse of $786-\mathrm{O}, 5 \times 10^{6}$ cells/mouse of $\mathrm{SCH}$ or $1 \times 10^{7}$ cells/mouse of 
A549. An $\sim 10-\mathrm{mm}^{3}$ fragment of SK-OV-3 tumor tissue was subcutaneously implanted in the right flank of each female mouse. Several weeks after tumor inoculation, mice bearing a tumor of $\sim 100-400 \mathrm{~mm}^{3}$ in volume were selected and were randomly allocated to control and treatment groups. Each group consisted of 6 mice. Tumor volume and body weight were measured once a week for 4 weeks starting from the first day of the treatment.

Tumor volume $(\mathrm{V})$ was estimated using the equation $\mathrm{V}=$ $a b^{2} / 2$, where $a$ and $b$ are the length and width of the tumor, respectively. Epoetin $\beta$ was subcutaneously administered once a week for 4 weeks at a dose of $1,000 \mathrm{IU} / \mathrm{kg}, 3,000 \mathrm{IU} / \mathrm{kg}$ or $10,000 \mathrm{IU} / \mathrm{kg}$ (11). Control mice received vehicle. To evaluate epoetin $\beta$ in combination with bevacizumab, bevacizumab was intraperitoneally administered once a week for 4 weeks (A549) or 3 weeks (MCF7) at a dose of $5 \mathrm{mg} / \mathrm{kg}$. The administration route and dosages of epoetin $\beta$ were the same as those used for epoetin $\beta$ as a single agent.

Statistical analysis. The Student's t-test was used to detect statistical differences in $\mathrm{Hb}$, hematocrit and red blood cell count. The Mann-Whitney U test was used to detect statistical differences in tumor volume and body weight. All statistical analyses were carried out using an SAS pre-clinical package (version 5.0; SAS Institute Inc., Tokyo, Japan).

\section{Results}

Hematopoietic effect of epoetin $\beta$ in BALB/c-nu/nu mice. $\mathrm{Hb}$ concentration, hematocrit and $\mathrm{RBC}$ were measured after epoetin $\beta$ administration. Fig. 1 shows the time course of the $\mathrm{Hb}$. A significant increase in Hb compared to the vehicle group was observed with both the $1,000 \mathrm{IU} / \mathrm{kg}$ group $(\mathrm{P}<0.05)$ and the $10,000 \mathrm{IU} / \mathrm{kg}$ group $(\mathrm{P}<0.01)$ as early as day 3 of the initial epoetin $\beta$ administration. Hb levels reached a plateau 1 week after the initiation of treatment, and were significantly $(\mathrm{P}<0.001-0.01)$ higher in the $10,000 \mathrm{IU} / \mathrm{kg}$ group than in the vehicle group from day 5 to 27 , while the $\mathrm{Hb}$ of the 1,000 IU/kg group was significantly higher on day $7(\mathrm{P}<0.01)$, day $13(\mathrm{P}<0.05)$ and day 20-27 $(\mathrm{P}<0.001)$ compared to the vehicle group. Similar results were obtained for hematocrit and RBC (Fig. 1).

Detection of EPO-R in human cancer cell lines. EPO-R expression was examined by RT-PCR in the MCF7, 786-O, SCH, A549 and SK-OV-3 human cancer cell lines used to generate the human cancer xenograft models. As shown in Fig. 2, all of the tumor cell lines expressed EPO-R mRNA. No PCR amplification products were observed in the negative control samples for any PCR reaction performed without reverse-transcription.

Effect of epoetin $\beta$ on tumor growth. The effect of epoetin $\beta$ on tumor growth was examined in the five human cancer cell lines, MCF7, 786-O, SCH, A549 and SK-OV-3, in mouse xenograft models. Tumor-bearing mice received a weekly administration of epoetin $\beta$ at a dose of $1,000,3,000$ or 10,000 $\mathrm{IU} / \mathrm{kg}$. All the tumors grew logarithmically during the entire course of the study. Throughout the experiments, no significant difference in tumor volume was observed at any dose between
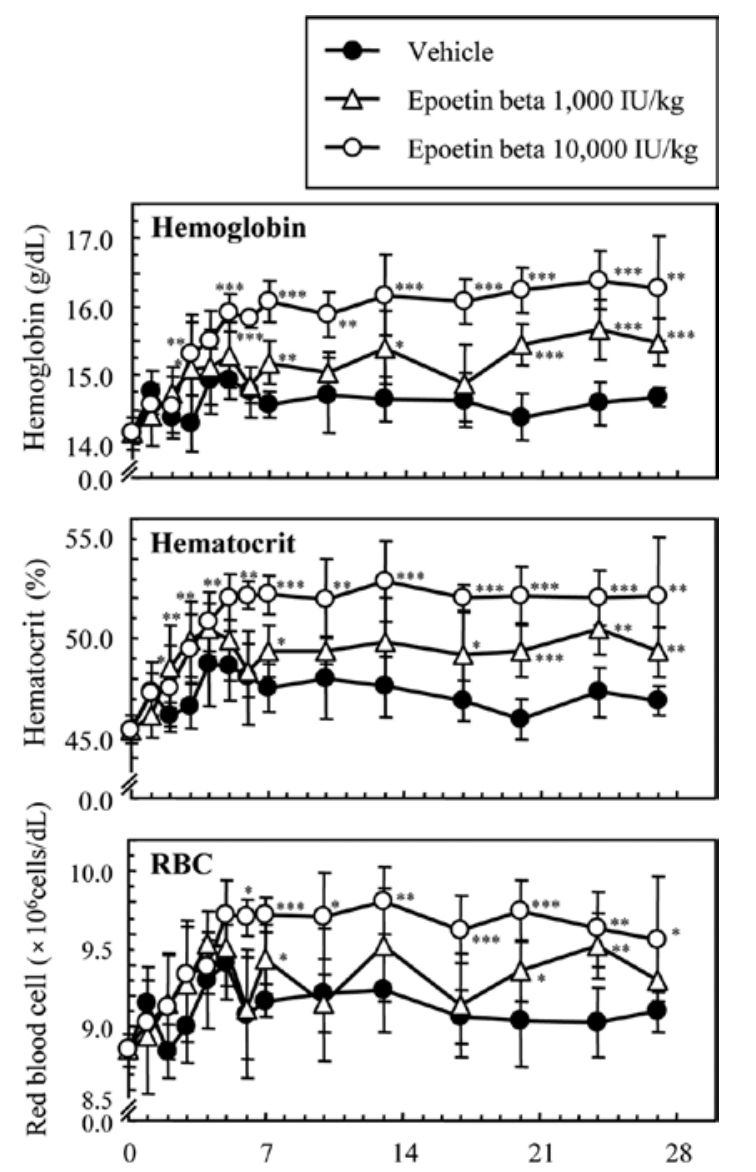

Days after start of treatment

Figure 1. Changes in the levels of $\mathrm{Hb}$, hematocrit and red blood cell count in BALB/c-nu/nu mice treated with epoetin $\beta$. Mice were randomly divided into 3 groups. A dose of 1,000 or $10,000 \mathrm{IU} / \mathrm{kg}$ of epoetin $\beta$ or vehicle was subcutaneously administered once a week for 4 weeks. On the indicated days, the 6 mice in each group were anaesthetized with diethyl ether and $0.6 \mathrm{ml}$ of blood was taken from the posterior vein using EDTA as an anticoagulant. The $\mathrm{Hb}$ level, hematocrit value and red blood cell count were determined using an ADVIA 120 automated blood analyzer. Data are expressed as the mean value \pm SD. The data on day 0 was obtained from the untreated group. Statistically significant differences between the vehicle group and each epoetin $\beta$-treated group are shown with asterisks. ${ }^{*} \mathrm{P}<0.05 ;{ }^{* *} \mathrm{P}<0.01 ;{ }^{* * *} \mathrm{P}<0.001$.

the epoetin $\beta$ group and the vehicle group for the 786-O, $\mathrm{SCH}$, A549 and SK-OV-3 cell lines (Fig. 3). For the MCF7 cell line, however, tumor volume was significantly reduced on day 7 in the $1,000 \mathrm{IU} / \mathrm{kg}$ epoetin $\beta$ group $\left(222 \pm 41 \mathrm{~mm}^{3} ; \mathrm{P}<0.01\right)$ and the $10,000 \mathrm{IU} / \mathrm{kg}$ epoetin $\beta$ group $\left(232 \pm 40 \mathrm{~mm}^{3} ; \mathrm{P}<0.05\right)$ compared to the vehicle group $\left(288 \pm 23 \mathrm{~mm}^{3}\right)$ (Fig. 3). No significant weight loss was observed in any of the models at any of the doses tested (data not shown).

To examine the effect of epoetin $\beta$ on the antitumor activity of an anti-angiogenic agent, epoetin $\beta$ was administered in combination with bevacizumab in the A549 and MCF7 xenograft models. Bevacizumab monotherapy showed significant antitumor activity compared to the vehicle in both xenograft models. In the A549 xenograft model, the tumor volume was $464 \pm 128 \mathrm{~mm}^{3}$ after 4 weeks of treatment with bevacizumab alone, whereas the tumor volumes were $456 \pm 145,481 \pm 132$ and $472 \pm 109 \mathrm{~mm}^{3}$ in mice treated with bevacizumab in combination with epoetin $\beta$ at 1,000, 3,000 and 10,000 IU/kg, respectively. In the MCF7 xenograft model, the tumor volume was $688 \pm 84$ 
EPO-R (557-1177, 621 bp)

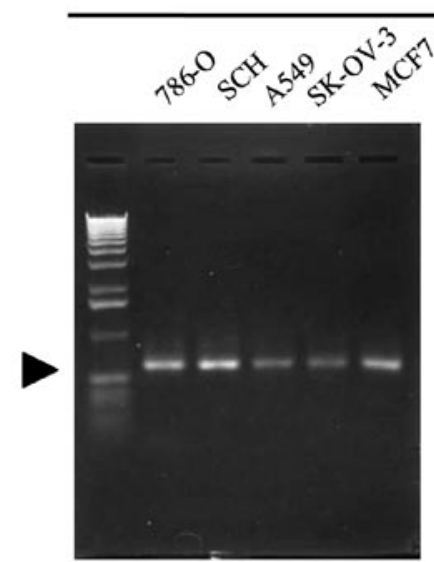

RT-PCR

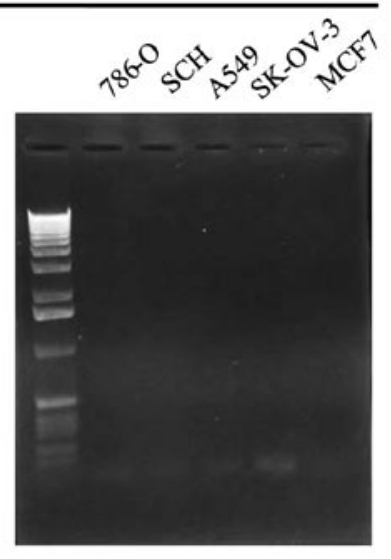

Negative Control

\section{$\beta$-actin (231-664, 434 bp)}

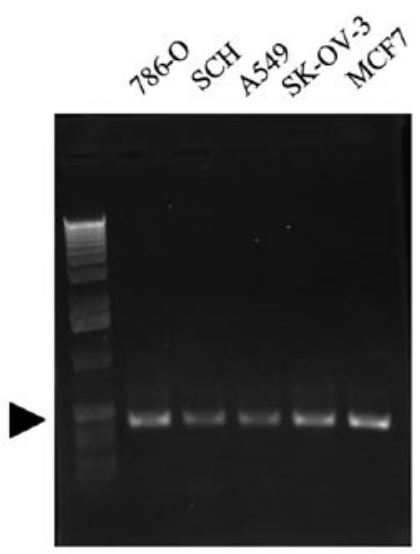

Internal Standard

Electrophoresis; 50V/h.

Figure 2. EPO-R expression in the five tumor cell lines. Total RNA was isolated from each tumor cell line and RT-PCR was performed on EPO-R and $\beta$-actin as described in Materials and methods. Arrows indicate specific fragments. As a negative control, the reaction was performed without the reverse-transcription of RNA.

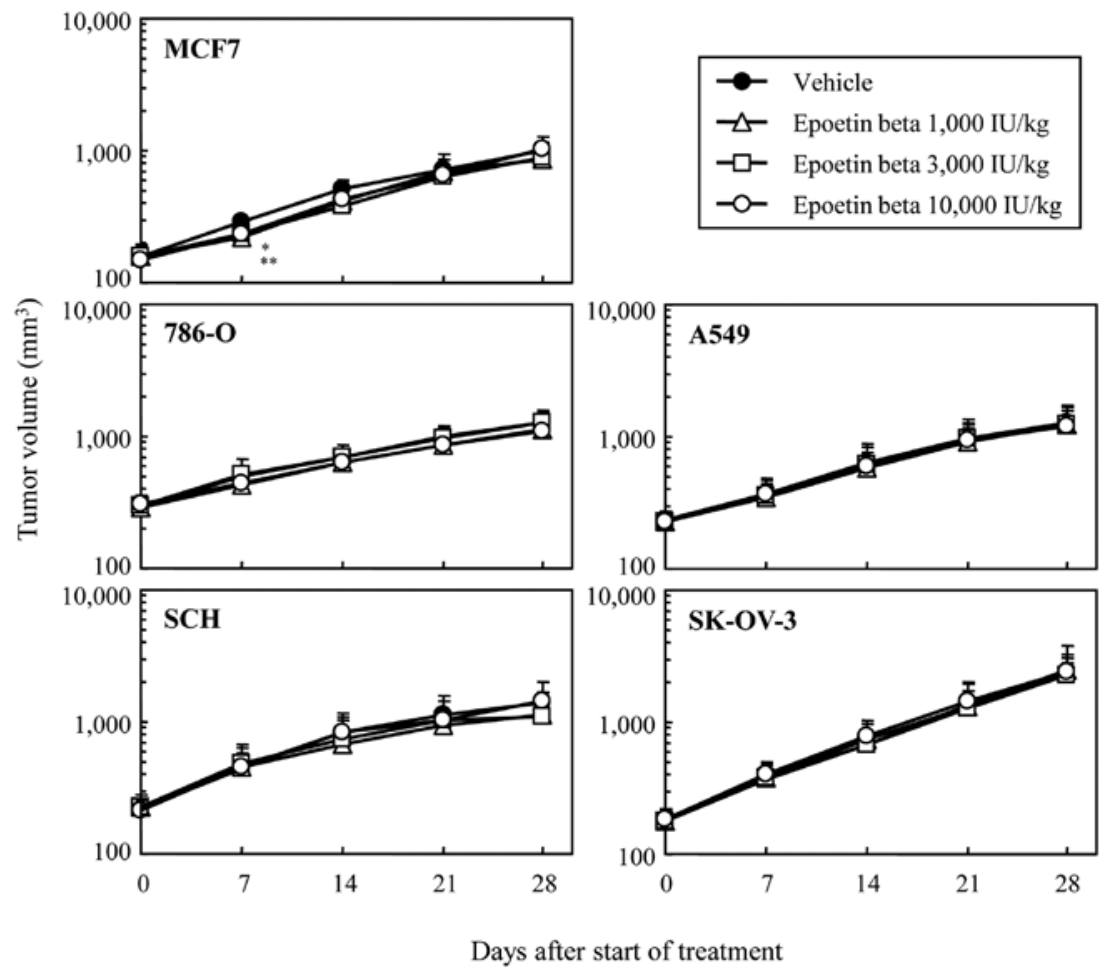

Figure 3. Effect of epoetin $\beta$ on tumor growth in human cancer xenograft models. Mice were randomly divided into groups of 6 . A dose of 1,000, 3,000 or $10,000 \mathrm{IU} / \mathrm{kg}$ of epoetin $\beta$ or vehicle was subcutaneously administered once a week for 4 weeks. Data are expressed as the mean value \pm SD of tumor volume $\left(\mathrm{mm}^{3}\right)$. Statistically significant differences between the vehicle group and each epoetin $\beta$-treated group are indicated with asterisks. ${ }^{*} \mathrm{P}<0.05 ;{ }^{* *} \mathrm{P}<0.01$.

$\mathrm{mm}^{3}$ after 3 weeks of treatment with bevacizumab alone and $729 \pm 114 \mathrm{~mm}^{3}$ in mice treated with bevacizumab in combination with epoetin $\beta$ at $10,000 \mathrm{IU} / \mathrm{kg}$ (Fig. 4A). Epoetin $\beta$ showed no significant effect on the antitumor activity of bevacizumab. $\mathrm{Hb}$ was elevated by treatment with epoetin $\beta$ in a dose-dependent manner regardless of bevacizumab treatment in each xenograft model. The elevated $\mathrm{Hb}$ level in mice treated with epoetin $\beta$ in combination with bevacizumab (Fig. 4B) was equivalent to that in mice treated with epoetin $\beta$ alone (Fig. 1). The $\mathrm{Hb}$ level of bevacizumab in the monotherapy group was the same as that of the vehicle group for each xenograft model (data not shown). 
A

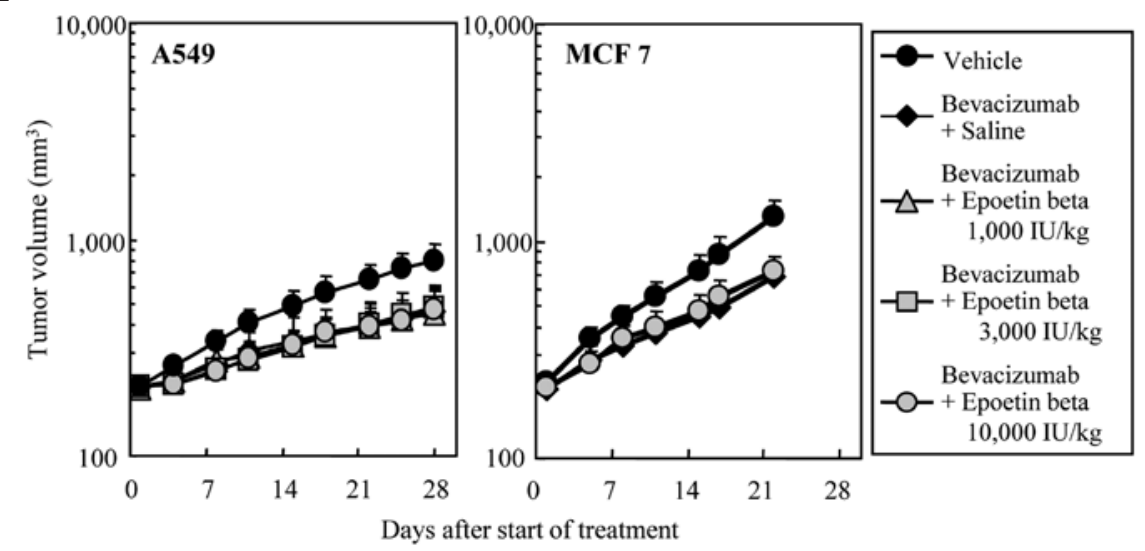

B

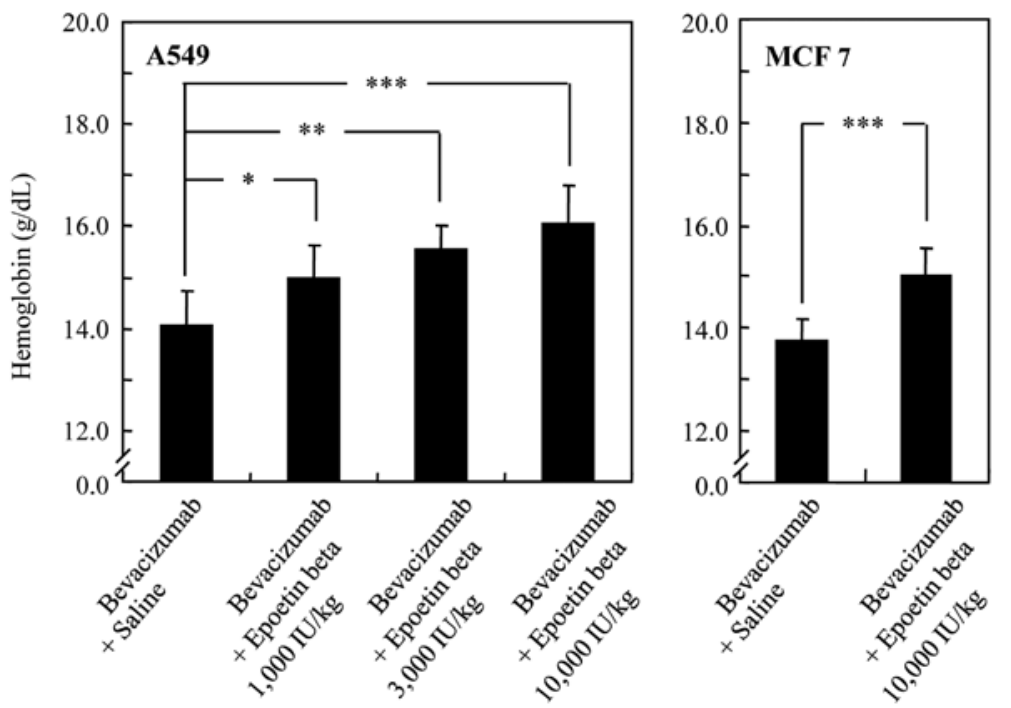

Figure 4. Effect of epoetin $\beta$ on the antitumor activity of bevacizumab. Mice were randomly divided into groups of 6 . Bevacizumab (5 mg/kg) was intraperitoneally administered once a week for 3 or 4 weeks. A dose of 1,000, 3,000 or 10,000 IU/kg of epoetin $\beta$ or vehicle was subcutaneously administered once a week for 3 or 4 weeks. (A) Tumor volumes are expressed as the mean value $\pm \mathrm{SD}\left(\mathrm{mm}^{3}\right)$. (B) Hb levels were measured using a Sysmex automated blood analyzer. Data are expressed as the mean value \pm SD. Statistically significant differences between the vehicle group and each epoetin $\beta$ group are indicated with asterisks. ${ }^{*} \mathrm{P}<0.05 ;{ }^{* *} \mathrm{P}<0.01 ;{ }^{* * *} \mathrm{P}<0.001$.

\section{Discussion}

We demonstrated that exogenous epoetin $\beta$ treatment did not affect tumor growth in mouse xenograft models using human tumor cells expressing EPO-R. It has been reported that EPO-R is expressed in several different types of human cancer cells, including cell lines and clinical specimens (24-30). However, studies on the in vitro proliferation of EPO-R-positive tumor cells treated with EPO have produced divergent results. Acs et al and Westenfelder et al described the EPO-dependent in vitro proliferation enhancement of 786-O human renal carcinoma cell lines and MCF7 human breast cancer cell lines, respectively $(25,27)$. In addition, the proliferation of a EPO-R-positive SCH gastric cancer cell line was modulated by endogenous EPO (26). On the other hand, Sugawa et al demonstrated that epoetin $\beta$ did not affect the in vitro proliferation of various tumor cell lines, including MCF7 and 786-O cells (32). In addition, Tovari et al and LaMontagne et al reported that EPO had no effect on the in vitro proliferation or the in vivo growth of EPO-R-positive human tumor cell lines, including epidermoid, colon and breast carcinoma $(33,34)$. These conflicting reports indicate that, at present, there is no consensus on the relationship between epoetin $\beta$ treatment and in vivo tumor growth. We were therefore motivated to conduct xenograft model experiments to help clarify the effect of epoetin $\beta$ on tumor growth.

In xenograft models, it is possible to examine the effects of rhEPO on tumor growth not only directly through EPO-R on tumor cells, but also indirectly through the stromal environment in tumor tissues, including tumor microvessels. In this context, we investigated the effects of epoetin $\beta$ on tumor growth in xenograft models using human cancer cell lines expressing EPO-R. Because a clinical trial demonstrated that once-weekly 40,000 U rhEPO therapy increases Hb levels and aids in the recovery from anemia of patients with cancer who have undergone concomitant chemotherapy (11), epoetin $\beta$ was administrated weekly for 4 weeks at the human equivalent dose of $1,000 \mathrm{IU} / \mathrm{kg}$ and at doses of 3,000 and 10,000 IU/kg to verify the overdose efficacy and safety in xenograft models. First, we evaluated the hematopoietic effect of epoetin $\beta$ in 
non-tumor-bearing $\mathrm{BALB} / \mathrm{c}-\mathrm{nu} / \mathrm{nu}$ mice in terms of $\mathrm{Hb}$, hematocrit and red blood cell count. For this experiment, epoetin $\beta$ was administered weekly for 4 weeks at doses of 1,000 and $10,000 \mathrm{IU} / \mathrm{kg}$. Levels of the three parameters were significantly increased within a few days of the initiation of epoetin $\beta$ treatment at both doses, indicating that the doses and administration schedule of epoetin $\beta$ in the xenograft models tested produce a significant hematopoietic effect in vivo.

The five tumor cell lines, MCF7, 786-O, SCH, A549 and SK-OV-3, were selected for the xenograft model experiments based on the reports cited above (MCF7, 786-O and SCH) and on the reported fact the highest incidence of anemia requiring EPO treatment occurred after chemotherapy in patients with lung and ovarian cancer (A549 and SK-OV-3) (38). In all the xenograft models used, weekly administration of epoetin $\beta$ had no significant effect on tumor growth enhancement, not only at the human equivalent dose of $1,000 \mathrm{IU} / \mathrm{kg}$, but also at doses as high as 3,000 and 10,000 IU/kg. These findings were consistent with the results of Tovari et al (33) and LaMontagne et al (34), even though the dose of EPO was considerably higher in our experiment. The level of EPO-R expression in the tumor cell lines used in the study was examined by RT-PCR. EPO-R mRNA was detected in all of the cell lines. We therefore concluded that exogenously administered epoetin $\beta$ does not promote tumor growth in human EPO-R-positive tumor cell xenograft models. The results suggest that epoetin $\beta$ neither acts directly on tumor cells through EPO-R nor works indirectly on the stromal environment in tumor tissues. Acrosoy et al reported the significance of EPO for the growth of rat mammary adenocarcinoma by using antagonists of EPO-EPO-R function in vivo (24). They also demonstrated the co-expression of EPO and EPO-R protein in primary breast tumors, suggesting the potential for the generation of an autocrine or paracrine growth stimulatory loop. Taken together, the results indicate that although EPO may be essential for the survival of specific kinds of tumor cells, exogenously administered EPO does not necessarily promote tumor growth.

Several studies have reported on the role of EPO in tumor neovascularization. Using tumor cells expressing EPO-R, Yasuda et al showed that the inhibition of angiogenesis by EPO-R antagonist administration led to a reduction in tumor mass (26). Hardee et al demonstrated that co-injection of rhEPO with tumor cells significantly stimulated tumor neovascularization and tumor growth in window chambers, and that co-injection of an anti-EPO antibody with tumor cells inhibited angiogenesis and impaired tumor growth (39). These findings possibly indicate that EPO administration impairs the effect of antitumor drugs, whose mode of action in tumor tissue is anti-angiogenesis. Bevacizumab is a humanized monoclonal antibody that neutralizes VEGF, inhibits the binding of VEGF to its receptors and exerts antitumor activity through the inhibition of tumor neovascularization (40). Therefore, we examined the effects of epoetin $\beta$ on the antitumor activity of bevacizumab in A549 and MCF7 xenograft models. We found that epoetin $\beta$ had no significant effect on the antitumor activity of bevacizumab, but that $\mathrm{Hb}$ levels were significantly increased, suggesting that epoetin $\beta$ did not affect angiogenesis in tumor tissues during bevacizumab treatment in these models.

Since rhEPO is used for the treatment of anemia caused by cancer chemotherapy, the effect of rhEPO on the antitumor activities of chemotherapeutic agents is of concern. Recently, Tovari et al demonstrated that the efficacy of 5-fluorouracil was improved in combination with rhEPO in human tumor xenograft models (33). LaMontagne et al showed no significant difference between the antitumor activity of paclitaxel alone and paclitaxel in combination with rhEPO in human breast carcinoma xenograft models (34). These results suggest that rhEPO does not impair the antitumor activity of chemotherapeutic drugs.

In conclusion, epoetin $\beta$ as a single agent as well as in combination with an anti-angiogenesis agent did not affect the growth of human tumor cell lines expressing EPO-R in xenograft models. However, the present study does not conclusively show that epoetin $\beta$ is not capable of promoting tumor progression without directly or indirectly enhancing tumor cell proliferation.

\section{References}

1. Jelkmann W: Erythropoietin: structure, control of production and function. Physiol Rev 72: 449-489, 1992.

2. Lacombe $\mathrm{C}$ and Mayeux P: The molecular biology of erythropoietin. Nephrol Dial Transplant 14: 22-28, 1999.

3. Tilbrook PA and Klinken SP: Erythropoietin and erythropoietin receptor. Growth Fancors 17: 25-35, 1999.

4. D'Andrea AD and Zon LI: Erythropoietin receptor. Subunit structure and activation. J Clin Invest 86: 681-687, 1990.

5. Ng T, Marx G, Littlewood T and Macdougall I: Recombinant erythropoietin in clinical practice. Postgrad Med J 79: 367-376, 2003.

6. Demetri GD, Kris M, Wade J, Degos L and Cella D: Quality-oflife benefit in chemotherapy patients treated with epoeitin $\alpha$ is independent of disease response or tumor type: Results from a prospective community oncology study. Procrit Study Group. J Clin Oncol 16: 3412-3425, 1998.

7. Littlewood TJ, Bajetta E, Nortier JWR, Vercammen E and Rapoport B: Effect of epoeitin alfa on hematologic parameters and quality of life in cancer patients receiving nonplatinum chemotherapy: Results of randomized, double-controlled trial. J Clin Oncol 19: 2865-2874, 2001.

8. Vansteenkiste J, Pirker R, Massuti B, et al: Aranesp 980297 study group: Double-blind placebo-controlled, randomized phase III trial of darbepoietin alfa in lung cancer patients receiving chemotherapy. J Natl Cancer Inst 94: 1211-1220, 2002.

9. Osterborg A, Brandberg Y,Molostava V,Losava G,Abdulkadyrov K, Hedenus M and Messinger D: Epoetin beta Hematorogy Study Group: randomized, double-blind, placebo-controlled trial of recombinant human erythropoietin, epoetin beta, in hematologic malignancies. J Clin Oncol 20: 2486-2494, 2002.

10. Rizzo JD, Lichtin AE, Woolf SH, et al: Use of epoetin in patients with cancer: evidence-based clinical practice guidelines of the American Society of Clinical Oncology and the American Society of Hematology. J Clin Oncol 20: 4083-4107, 2002.

11. Gabrilove JL, Cleeland CS, Livingston RB, Sarokhan B, Winer E and Einhorn LH: Clinical evaluation of once-weekly dosing of epoetin alfa in chemotherapy patients: improvements in hemoglobin and quality of life are similar to three-time-weekly dosing. J Clin Oncol 19: 2875-2882, 2001.

12. Bohlius J, Langensiepen S, Schwarzer G, Seidenfeld J, Piper M, Bennett $C$ and Engert A: Recombinant human erythropoietin and overall survival in cancer patients: results of a comprehensive meta-analysis. J Natl Cancer Inst 97: 489-498, 2005.

13. Glaser CM, Millesi W, Kornek GV, et al: Impact of hemoglobin level and use of recombinant erythropoietin on efficacy of preoperative chemoradiation therapy for squamous cell carcinoma of the oral cavity and oropharynx. Int J Rad Oncol Biol Phys 50: 705-715, 2001.

14. Henke M, Laszig R Rube C, et al: Erythropoietin to treat head and neck cancer patients with anaemia undergoing radiotherapy: randomized, double-blind, placebo-controlled trial. Lancet 362: 1255-1260, 2003.

15. Leyland-Jones B, Semiglazov V, Pawlicki M, et al: Maintaining normal hemoglobin levels with epoeitin $\alpha$ in mainly nonanemic patients with metastatic breast cancer receiving first-line chemotherapy: a survival study. J Clin Oncol 23: 5960-5972, 2005. 
16. Wright JR, Ung YC, Julian JA, et al: Randomized, double-blind, placebo-controlled trial of erythropoietin in non-small cell lung cancer with disease-related anemia. J Clin Oncol 25: 1027-1032, 2007.

17. Rizzo JD, Somerfield MR, Hagerty KL, et al: Use of epoetin and darbepoetin in patients with cancer: 2007 American Society of Hematology/American Society of Clinical Oncology clinical practice guideline update. Blood 111: 25-41, 2008.

18. Juneja V, Keegan P, Gootenberg JE, et al: Continuing Reassessment of the risks of erythropoiesis-stimulating agents in patients with cancer. Clin Cancer Res 14: 3242-3247, 2008.

19. D'Andrea AD and Zon LI: Erythropoietin receptor: subunit structure and activation. J Clin Invest 86: 681-687, 1990.

20. Farrell $\mathrm{F}$ and Lee A: The erythropoietin receptor and its expression in tumor cells and other tissues. Oncologist 9: 18-30, 2004.

21. Jelkmann W and Wangner K: Beneficial and ominous aspects of the pleiotropic action of erythropoietin. Ann Hematol 83: 673-686, 2004

22. Anagnostou A, Liu Z, Steiner M, Chin K, Lee ES, Kessimian N and Noguchi CT: Erythropoietin receptor mRNA expression in human endotherial cells. Proc Natl Acad Sci USA 91: 3974-3978, 1994.

23. Wu H, Lee SH, Gao J, Liu X and Iruela-Arispe ML: Inactivation of erythropoietin leads to defects in cardiac morphogenesis. Development 126: 3597-3605, 1999.

24. Arcasoy MO, Amin K, Karayal AF, Chou SC, Raleigh JA, Varia MA and Haroon ZA: Functional significance of erythropoietin receptor expression in breast cancer. Lab Invest 82: 911-918, 2002.

25. Acs G, Acs P, Beckwith SM, Pitts RL, Clements E, Wong K and Verma A: Erythropoietin and erythropoietin receptor expression in human cancer. Cancer Res 61: 3561-3565, 2001.

26. Yasuda Y, Fujita Y, Matsuno T, et al: Erythropoietin regulates tumor growth of human malignancies. Carcinogenesis 24: 1021-1029, 2003.

27. Westenfelder C and Baranowski RL: Erythropoietin stimulates proliferation of human renal carcinoma cells. Kidney Int 58 647-657, 2000.

28. Arcasoy MO, Jiang X and Haroon ZA: Expression of erythropoietin receptor splice variants in human cancer. Biochem Biophys Res Commun 362: 999-1007, 2003.

29. Arcasoy MO, Amin K, Vollmer RT, Jiang X, DemarkWahnefried W and Haroon ZA: Erythropoietin and erythropoietin receptor expression in human prostate cancer. Mod Pathol 18: 421-430, 2005.
30. Selzer E, Wacheck V, Kodym R, Schlagbauer-Wadl H, Schlegel W, Pehamberger H and Jansen B: Erythropoietin receptor expression in human melanoma cells. Melanoma Res 10: 421-426, 2000.

31. Rosti V, Pedrazzoli P, Ponchio L, Zibera C, Novella A, Lucotti C, Della Cuna GR and Cazzola M: Effect of recombinant human erythropoietin on hematopoietic and non-hematopoietic malignant cell growth in vitro. Haematologica 78: 208-212, 1993.

32. Sugawa M and Fukui H: Effects of recombinant human erythropoietin on the growth of various human tumor cells. Biotherapy 19: 181-196, 2005.

33. Tovari J, Gilly R, Raso E, Paku S, Bereczky B, Varga N, Vago A and Timar J: Recombinant human erythropoietin $\alpha$ targets intratumoral blood vessel, improving chemotherapy in human xenograft models. Cancer Res 65: 7186-7193, 2005.

34. LaMontagne KR, Butler J, Marshall DJ, Tullai J, Gechtman Z, Hall C, Meshaw A and Farrell FX: Recombinant epoetins do not stimulate tumor growth in erythropoietin receptor-positive breast carcinoma models. Mol Cancer Ther 5: 347-355, 2006.

35. Silver DF and Piver MS: Effects of recombinant human erythropoietin on the antitumor effect of cisplatin in SCID mice bearing human ovarian cancer: a possible oxygen effect. Gynecol Oncol 73: 280-284, 1999.

36. Mittelman M, Nemann D, Peled A, Kanter P and Haran-Ghera N: erythropoietin induces tumor regression and antitumor immune responses in murine myeloma models. Proc Natl Acad Sci USA 98: 5181-5186, 2001

37. Okazaki T, Ebihara S, Asada M, Yamanda S, Niu K and Arai $H$ : Erythropoietin promotes the growth of tumors lacking its receptor and decreases survival of tumor-bearing mice by enhancing angiogenesis. Neoplasia 10: 932-939, 2008.

38. Tas F, Eralp Y, Basaran M, et al: Anemia in oncology practice: Relation to diseases and their therapies. Am J Clin Oncol 25: 371-379, 2002.

39. Hardee ME, Cao Y, Fu P, et al: Erythropoietin blockade inhibits the induction of tumor angiogenesis and progression. PLoS One 2: e549, 2007.

40. Eskens FA and Sleijfer S: The use of bevacizumab in colorectal, lung, breast, renal and ovarian cancer: where does it fit. Eur J Cancer 44: 2350-2356, 2008. 